\title{
Proteins Associated with Cardiac Neural Crest in the Pharyngeal Region of Early Chick Embryos
}

\author{
RA-ID ABDULLA, EDWIN F. SLOTT, AND MARGARET L. KIRBY \\ Departments of Cellular Biology and Anatomy [E.F.S., M.L.K.] and Pediatrics [R.A., M.L.K.], Medical College \\ of Georgia, Augusta, Georgia 30912-2000
}

\begin{abstract}
Normal septation and alignment of the outflow tract of the heart depends on ectomesenchymal cells derived from the cardiac neural crest. Removal of the premigratory cardiac neural crest results in a variety of cardiac anomalies. The sequence of events leading to these cardiac anomalies in the absence of the cardiac neural crest cell population is not fully understood. This study is the first in a series directed at understanding the role of the neural crest in cardiovascular development at the molecular level. We have begun by distinguishing proteins uniquely expressed by, or responding to the presence of, cardiac neural crest cells in the pharyngeal apparatus, as well as proteins that are seen in the absence of cardiac neural crest cells. Cardiac neural crest was removed by microcautery from stage 9 to 10 embryos. At stages 14, 18, and 21, the protein patterns in the pharyngeal regions of experimental and sham-operated embryos were compared using isoelectric focusing followed by SDS-polyacrylamide gel electrophoresis. Five proteins were found in sham-operated embryos at stages 14 and 18 that could not be seen in embryos with neural crest ablations. Four proteins were found in embryos with neural crest ablation at stages 14 and 18 that were not seen in sham-operated embryos. By stage 21 , the protein patterns of both sham-operated and experimental embryos were identical. These results indicate that there may be a compensatory response to neural crest ablation as development proceeds. (Pediatr Res 33: 43-47, 1993)
\end{abstract}

\section{Abbreviations}

IEF, isoelectric focusing

DNase, deoxyribonuclease

RNase, ribonuclease

Cells migrating from the neural crest located on the neural axis between the midotic placode and the caudal boundary of somite 3, also known as the cardiac neural crest (Fig. 1), play an important role in the development of the heart and great arteries as well as noncardiovascular structures derived from the pharyngeal apparatus (1-4). In the chick embryo, cardiac neural crest cells migrate shortly after the neural tube has closed. The cells migrating from the cardiac neural crest via the dorsolateral pathway arrest their migration in the circumpharyngeal region before the formation of the pharyngeal arches (5). Cells from the circumpharyngeal crest populate pharyngeal arches 3 , 4, and 6 as they are formed. In the pharyngeal arches, the cells provide an ectomesenchymal sheath surrounding each of the aortic arch

Received January 10, 1992; accepted September 15, 1992

Correspondence: Dr. Margaret L. Kirby, Department of Cellular Biology and Anatomy, Medical College of Georgia, Augusta, Georgia 30912-2000.

Supported by PHS grant HL-36059. arteries (6). These cells provide precursors to nervous tissue and much of the ectomesenchyme to support various aspects of cardiovascular and glandular development in the pharyngeal region. The neural derivatives form the postsynaptic parasympathetic innervation of the heart, thorax, and abdomen, while the ectomesenchymal tissue surrounds the aortic arch arteries to provide support and ultimately develop into the tunica media of the great arteries $(7,8)$. Some neural crest-derived cells from these arches continue their migration into the cardiac outflow tract where they play a crucial role in forming the outflow septation complex $(1,9)$.

The ectomesenchymal component of the cardiac neural crest is determined early. Transplantation studies have shown that other areas of the neural crest that contain ectomesenchymal cells are not capable of supporting cardiovascular development (10). Because the transplantation was done at the neural fold stage of development (stage 9), it was inferred that the mesenchymal component of the cranial region of the neural crest is determined early in development. The idea that the neural crest attains a segmental identity early in development is supported by the regional expression of various homeotic messages (11) as well as a rather strict segmental origin of neural crest cells in the cranial region (12).

Normal development of noncardiovascular structures in the pharyngeal apparatus is also dependent upon cardiac neural crest-derived cells in pharyngeal arches 3,4 , and $6(3,4)$. These structures include the thymus, parathyroid, and thyroid glands. The continuity between abnormal septation of the outflow tract and abnormal development of these glands is evident in the clinical entity of DiGeorge syndrome, which is now thought to be a result of abnormal development of the cardiac neural crest (4).

The function of the cardiac neural crest cells is partially compensated when it is bilaterally ablated, by cells derived from the nodose placodes $(13,15)$. As much as $70 \%$ of postsynaptic parasympathetic innervation is present in hearts of chick embryos with bilateral ablation of the cardiac neural crest (14). Ectomesenchymal tissue supporting the aortic arch arteries and cardiac outflow septation is also reconstituted by cells derived from the nodose placodes (15). However, cells derived from the nodose placodes are unable to participate in normal outflow septation (15) or manufacture normal vessel wall components (16). Consequently, outflow tract anomalies occur (15), and the tunica media of the great arteries is delayed in acquiring its elastic matrix (16). The deficient wall support of the aortic arch arteries and other changes in the pharyngeal apparatus could explain the early and significant hemodynamic changes noted in stage 18 chick embryos by Leatherbury et al. (17) and Tomita et al. (18). Such early hemodynamic changes cannot be explained by failure of outflow tract septation, inasmuch as this septation does not occur until stages 25-27.

The role of the cardiac neural crest cells in the pharyngeal apparatus may be better understood through their molecular activities in this region. Using IEF in conjunction with SDS- 


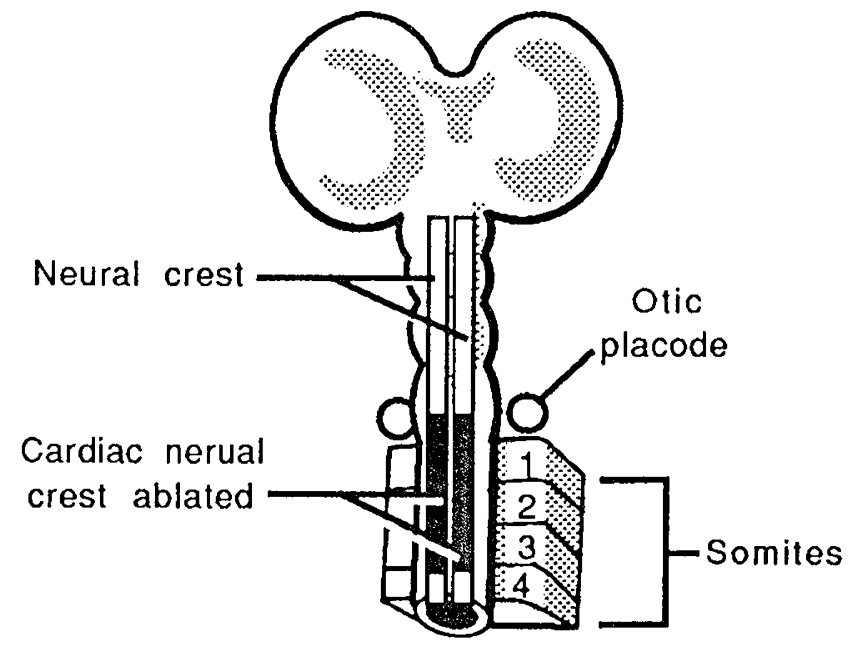

Fig. 1. Diagram illustrating the extent of the cardiac neural crest on the neural axis.

PAGE, we have discovered the presence of several proteins produced by or in response to cardiac neural crest cells in the pharyngeal apparatus during early stages of development, as well as proteins produced by cells in the absence of cardiac neural crest cells. Differences in proteins produced in these embryos are lost as development proceeds.

\section{MATERIALS AND METHODS}

Fertilized Arbor Acre chicken eggs were incubated in forceddraft incubators at $38^{\circ} \mathrm{C}$. Relative humidity during incubation was $97 \%$. All eggs were windowed and stained (19) at stages 910 of Hamilton and Hamburger (20) and the vitelline membrane torn in preparation for bilateral ablation of the cardiac neural crest by microcautery as described previously (2). In a single day, a total of 16 to 28 embryos were obtained for surgery. Half of the embryos underwent microcautery of the cardiac neural crest (Fig. 1). The other half served as surgical shams that had been subjected, in parallel, to all of the surgical procedures with the exception of microcautery ablation. The eggs were returned to the incubator to allow further maturation of the embryos. Experimental embryos (bilateral cardiac neural crest ablation) and sham-operated embryos (intact cardiac neural crest) were harvested at stages 14, 18, and 21 (18). In each harvest, an equal number of embryos from both experimental and sham-operated groups were dissected by the same individual (M.L.K.) so as to maintain consistency. Dissection was performed with the aid of a stereomicroscope. For the purposes of these experiments, the pharyngeal apparatus was defined to extend from the cranial end of the third pharyngeal arch to the caudal end of the sixth pharyngeal arch region (Fig. 2). This region was separated from the remaining parts of the embryonic head and trunk and the heart, which connects to the pharyngeal apparatus by the cardiac outflow tract. A single pharyngeal apparatus was collected for each gel. A total of at least 20 pharyngeal apparatuses was collected from each stage to be analyzed. In preliminary experiments, it was found that there was not sufficient protein at stage 14 to obtain reproducible protein patterns after electrophoresis, and so in subsequent experiments, the pharyngeal apparatuses were pooled from 10 to 20 embryos at this stage. At stages 18 and 21 , a single pharyngeal apparatus was processed to produce a single gel. The tissue was prepared using a slightly modified version of the protocol recommended by Garrels (21). Each pharyngeal apparatus was placed in an Eppendorf tube containing $100 \mu \mathrm{L}$ of $1.5 \mathrm{mM}$ Tris buffer (pH 7.4) containing $10 \mu \mathrm{g} / \mathrm{mL}$ protease-free DNase 1 (Worthington, Enzymes \& Biochemicals for Life Science Research, Freehold, NJ), $5 \mu \mathrm{g} / \mathrm{mL}$ protease-free RNase A (Worthington) and $0.1 \mathrm{mM}$ phenylmethane sulfonyl

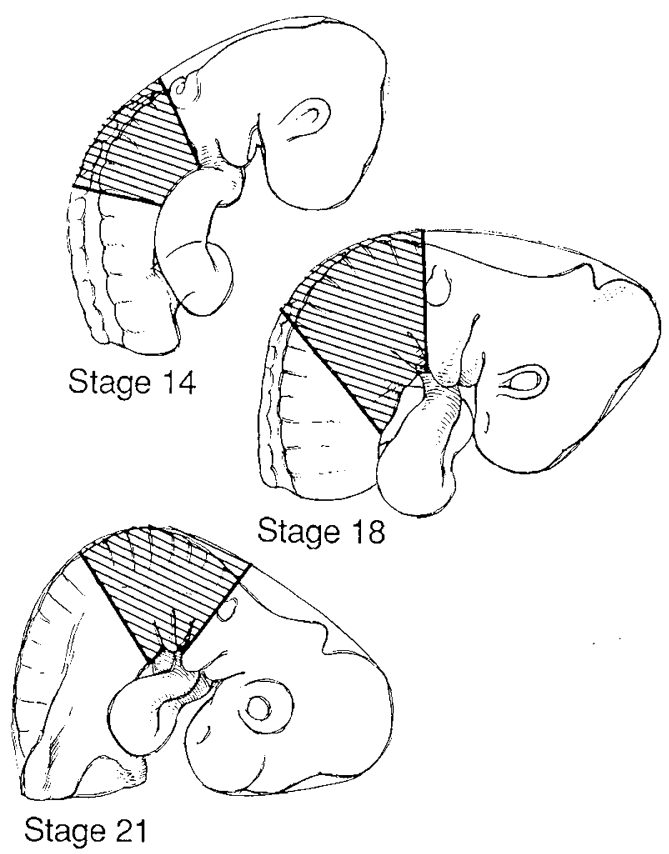

Fig. 2. Diagrams of stage 14,18 , and 21 embryos to illustrate the region dissected for analysis by two-dimensional gel electrophoresis. The postotic portion of the pharyngeal region was analyzed. It extends from the cranial border of the third pharyngeal arch to the caudal border of the sixth pharyngeal arch region and was dissected free of the embryo and the heart.

fluoride (Sigma Chemical Co., St. Louis, MO), and homogenized for $20 \mathrm{~s}$ on ice using a hand held Omni 1000 tissue homogenizer. Phenylmethane sulfonyl fluoride was used to inhibit the activity of serine type proteases, the most commonly encountered type in blood. Other protease types, although present, are usually identified with specific organ systems. For example, metallo- and cysteine-proteases are usually associated with the digestive system (22). For these experiments, we separated the pharyngeal regions from organs that could contribute these contaminants and interfere with the results. If protease activity were present, one would expect to find an increase in low molecular weight products as well as reduced rather than absent bands. In addition, all experiments were carried out at $4^{\circ} \mathrm{C}$ under denaturing conditions. Proteases encountered in chick embryos have an optimum temperature of $38^{\circ} \mathrm{C}$. RNase and DNase were found to improve the quantity and quality of proteins observed $(21,23)$. The homogenate was immediately frozen in liquid nitrogen and lyophilized overnight. The dried sample was resuspended in IEF buffer consisting of freshly prepared 9.5 M ultra-pure urea (Bio-Rad Laboratories, Richmond, CA), 2\% Nonidet P-40 (Sigma), and $2 \%$ ampholyte (LKB Instruments, Inc., Gaithersburg, MD) (23, 24). The protein concentration was measured using the Bradford method (25).

In preliminary experiments, the homogenates of stage 18 embryos were digested for $0-30$ min with testicular hyaluronidase $(0.1 \mathrm{mg} / \mathrm{mL})$ or chondroitinase $\mathrm{ABC}(0.1 \mathrm{U} / \mathrm{sample}$ was found in preliminary experiments to digest glycocongugates completely).

The Bio-Rad Mini-Protean system for IEF-SDS-PAGE was used. First-dimension IEF gels (23) with pI ranges of $3-10$ or 58 were loaded with $40 \mu \mathrm{g}$ of protein in $20-25 \mu \mathrm{L}$ of loading buffer. The sample was overlaid with an equal volume of buffer containing $9 \mathrm{M}$ urea, $1 \%$ ampholyte with a $\mathrm{pH}$ range corresponding to that in the sample buffer and $0.005 \%$ Bromophenol blue. Before loading the sample, the first-dimension gels were preelectrophoresed at $200 \mathrm{~V}$ for $10 \mathrm{~min}, 300 \mathrm{~V}$ for $15 \mathrm{~min}$, and $400 \mathrm{~V}$ for $15 \mathrm{~min}$. After the samples were added, the gels were routinely run at $500 \mathrm{~V}$ for $10 \mathrm{~min}$ and $750 \mathrm{~V}$ for $4 \mathrm{~h}$. IEF was determined 
in preliminary experiments to be complete after $4 \mathrm{~h}$. Samples from sham-operated and experimental embryos of each stage were run in pairs to control for environmental variables. When IEF was complete, the gels were extracted from the tubes and equilibrated in denaturing buffer for $2 \mathrm{~h}$. They were attached with $1 \%$ agarose in SDS sample buffer to the top of $10 \%$ SDSPAGE slab gels. The SDS-PAGE second dimension included a $10 \%$ acrylamide separating gel with a $5 \%$ acrylamide stacking gel using a discontinuous buffer system as described by Laemmli (26). Ten percent was determined in preliminary experiments to obtain the best separation of the bulk of proteins in the pharyngeal apparatus. The slab gels were electrophoresed for $0.5-1.5 \mathrm{~h}$ at $150 \mathrm{~V}$. Sham-operated and experimental samples were run in parallel. The slab gels were stained twice for demonstration of proteins in low abundance, as recommended by the protocol using a silver kit (Bio-Rad) to visualize proteins.

\section{RESULTS}

Viability of the embryos to stages 14 through 21 ranged from $70-90 \%$. The viability of embryos with cardiac neural crest ablations to d 11 of incubation is usually about $30 \%$ with an incidence of persistent truncus arteriosus of $80-100 \%$. It has been shown previously that the embryos that survive to $d 11$ of incubation are a selected population in which the cardiac output is higher than in control embryos (18). The stages chosen for this study represent a time period before this selection process and hence a mixed population of embryos with regard to survival potential.

Although it was possible to visualize the proteins from individual stage 14 pharyngeal regions, the resolution was improved by pooling the pharyngeal samples at this age. The optimum results were obtained when pharyngeal regions of 10 embryos were pooled to obtain sufficient protein $(20-40 \mu \mathrm{g})$ at stage 14 for resolution on two-dimensional gels. The pharyngeal regions of individual embryos were used at stages 18 and 21 to generate single two-dimensional gels. Each stage was repeated a minimum of five times in each of the ampholyte focusing gradients (3-10 or 5-8) followed by SDS-PAGE at 7, 10, 12, or $17 \%$ acrylamide concentration. Visualization of the proteins that were different was optimized at an ampholyte gradient of 5-7 and SDS-PAGE acrylamide concentration of $10 \%$. Although these parameters restrict the molecular weight and isoelectric points of the proteins analyzed, we found that the proteins outside this range were difficult to compare from gel to gel. Hence, the proteins identified in this study are those that yielded consistent results on the majority of the gels.

Ovalbumin $(\mathrm{pl}=6.6$, molecular mass $=42 \mathrm{kD}$ ) was naturally present in all of the samples and served as an internal standard.

At stage 14, four proteins were found on 2-dimensional gels of samples from the pharyngeal regions of sham-operated embryos that could not be seen on comparable gels of experimental embryos (Table 1, Fig. 2). All four proteins had pI in the 5.57.0 range and molecular masses ranging from 42 to $70 \mathrm{kD}$. One protein $(\mathrm{pI}=7.25$, molecular mass $=42 \mathrm{kD})$ was found in gels of the experimental embryos but was not present in shamoperated embryos (Fig. 3, Table 1). Proteins $>150 \mathrm{kD}$ or $<20$ $\mathrm{kD}$ were not resolved in this system.

At stage 18, one protein was found in gels of the sham-operated embryos that was not present in experimental embryos (Table 1 , Fig. 4). This protein had a pI of 7.0 and a molecular mass of 45 $\mathrm{kD}$. Three proteins that were not present in sham-operated embryos were found on gels of experimental embryos. These proteins had $\mathrm{pI}$ ranges of 6.0-7.25 and widely divergent molecular mass $(35,42$, and $97 \mathrm{kD})$. The protein located at pI 7.25 and molecular mass $42 \mathrm{kD}$ had characteristics similar to the same protein found in experimental embryos at stage 14. Digestion of the homogenates before IEF, using testicular hyaluronidase or chondroitinase $\mathrm{ABC}$, resulted in disappearance of this protein, indicating that it is probably a matrix component.

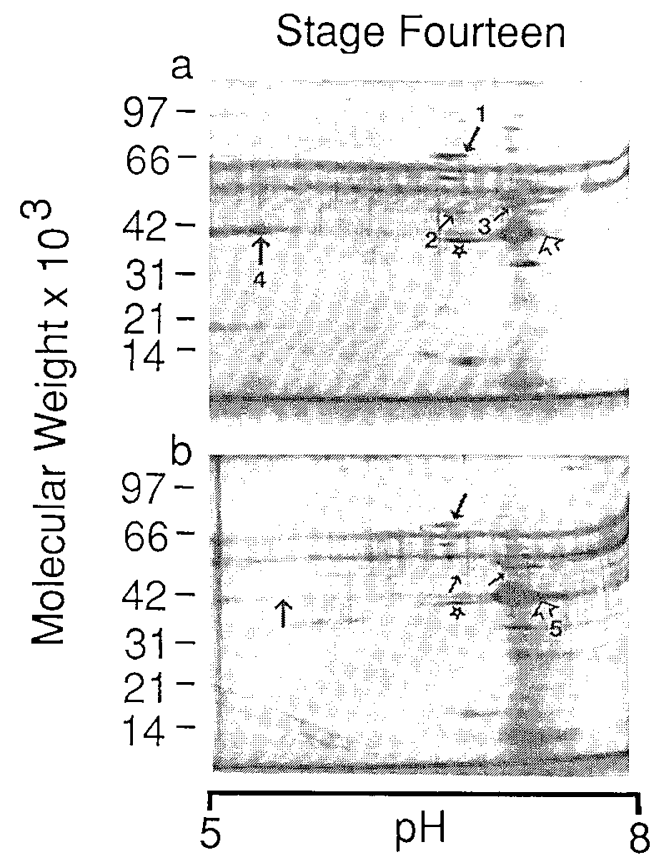

Fig. 3. Two-dimensional gels of stage 14 pharyngeal region. A total of four proteins $(1-4)$ can be seen in sham-operated embryos $(a)$ that are missing in experimental embryos $(b)$. One protein at $42 \mathrm{kD}$ is seen in the experimental embryos but is missing in the sham embryos. *, ovalbumin.

Table 1. Isoelectric points and molecular masses of proteins expressed in the pharyngeal region of sham-operated or experimental embryos at stages 14 and 18 after cardiac neural crest ablation

\begin{tabular}{clcc}
\hline Protein & pI & Molecular mass (kD) & Sham/experimental \\
\hline Stage 14 & & & \\
1 & 6.5 & 70 & $+/-$ \\
2 & 6.5 & 50 & $+/-$ \\
3 & 7.0 & 50 & $+/-$ \\
4 & 5.5 & 42 & $+/-$ \\
$5^{*}$ & 7.25 & 42 & $-/+$ \\
Stage 18 & & & $+/-$ \\
1 & 7.0 & 25 & $-/+$ \\
2 & 6.5 & 35 & $-/+$ \\
$3^{*}$ & 7.25 & 42 & $-/+$ \\
4 & 6.75 & 97 & \\
\hline
\end{tabular}

* Protein digested with hyaluronidase and chondroitinase ABC.

By stage 21, the protein patterns of samples from experimental and sham-operated embryos were strikingly similar (Fig. 5). No consistent differences could be found on gels from embryos at this stage. The protein found in stage-14 and -18 experimental embryos had disappeared.

\section{DISCUSSION}

This study has shown five proteins that are uniquely associated with the presence of cardiac neural crest cells in the pharyngeal apparatus at stages 14 and 18 of chick development. Stage 14 is approximately $48 \mathrm{~h}$ of development, whereas stage 18 is approximately $72 \mathrm{~h}$ of development. Hence, the separation in time between these two stages is only about $24 \mathrm{~h}$. Even so, the protein patterns of the pharyngeal apparatus at these two different stages are quite different. The proteins that were seen in gels of embryos with an intact neural crest may be produced by the neural crest cells themselves or by some other cell type located in the pharyngeal region in response to the presence of the cardiac neural crest cells. Four (or possibly three) additional proteins are associated 


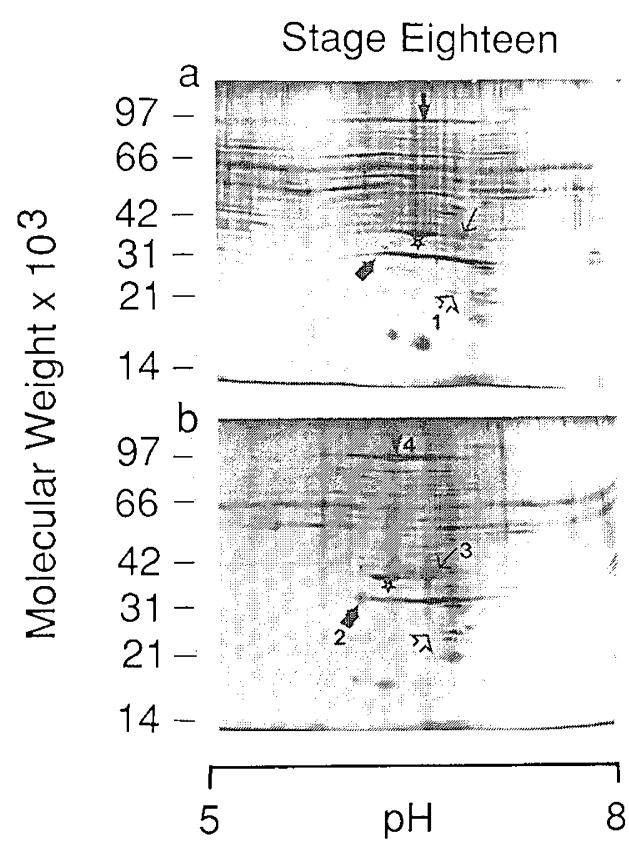

Fig. 4. Two-dimensional gels of stage 18 pharyngeal region. One protein $(l)$ that is missing from the experimental embryo $(b)$ can be seen in the sham-operated embryo $(a)$. Three proteins are seen in the experimental embryo that are not present in the sham-operated embryo. Note that protein 3 in $(b)$ is in the same position as protein 5 in Figure $3 b$. , ovalbumin.

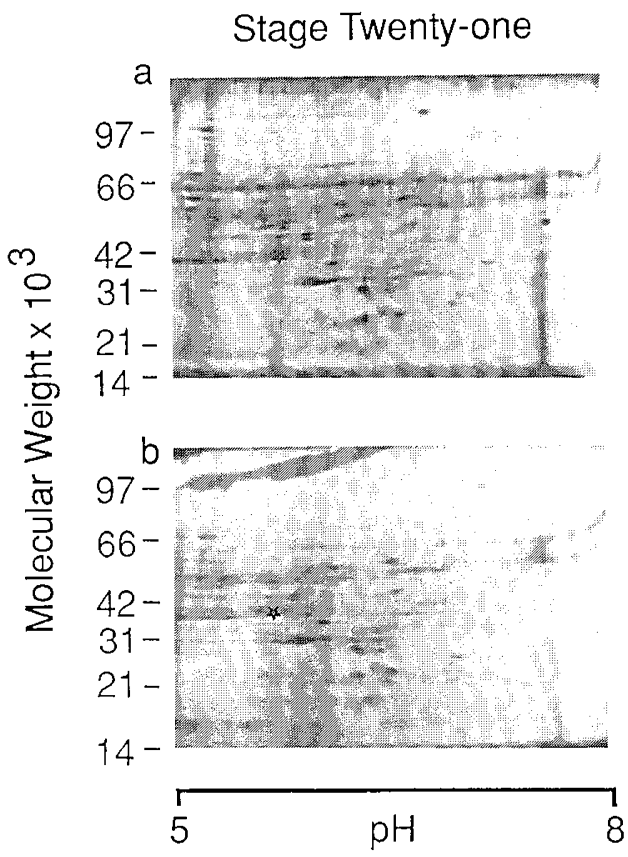

Fig. 5. Two-dimensional gels of stage 21 pharyngeal region. The protein patterns of sham-operated $(a)$ and experimental embryos $(b)$ are the same. ${ }^{*}$, ovalbumin.

with the absence of cardiac neural crest cells in the pharyngeal region. These proteins may be produced in response to the lack of neural crest cells or they may not be normally degraded or transformed in the absence of the neural crest.

The similarity of protein patterns in stage- 21 chick embryos with and without cardiac neural crest ablation might be interpreted to mean that the unique role of cardiac neural crest cells in this region is completed after stage 18 and before stage 21 . On the other hand, it could also indicate that the stage 21 embryo has compensated for the loss of the cardiac neural crest cell population. These interpretations are consistent with the morphologic events occurring in the pharyngeal apparatus, which include the population of pharyngeal arches 3-6 during the time period between stages 14 and $18(5,9)$. By stage 21 , the neural crest cells have fully populated these arches, and migration has been initiated into the outflow tract of the developing heart where they will participate in forming the outflow septation complex. In the present study, the heart and outflow tract were not included in the tissue sampled in order to analyze the pharyngeal compartment without the added complexity of cardiac-associated proteins.

The finding that the pharyngeal protein patterns at stage 21 are similar in sham-operated and experimental embryos does not preclude other changes in the normal pattern of development as the cells migrate into other more distal targets, e.g. the outflow region of the heart.

The protein at pl 7.25 and molecular mass $42 \mathrm{kD}$, found in experimental embryos at stages 14 and 18 but disappearing by stage 21 is most likely associated with the matrix. This protein is found in the same position in IEF-SDS-PAGE gels of heart at the same stages of development (unpublished data). The relatively large quantity of this protein and its behavior on treatment with chondroitinase lead to the assumption that it is one of the glycoconjugate components of the cardiac jelly $(28,29)$. Its presence in the pharyngeal region in experimental embryos, but not in sham-operated embryos, is puzzling but perhaps represents displacement of cardiac jelly as a spatial surrogate for the missing neural crest cells.

Any protein uniquely expressed in the pharyngeal apparatus of chick embryos with intact cardiac neural crest may be hypothetically associated with a number of developmental events related to cardiovascular development, such as normal development of the supportive tissue of the aortic arch arteries and cardiac outflow tract. The significance of this may be substantial, inasmuch as the hemodynamic changes noted at earlier stages of development of chick embryos with ablated cardiac neural crest $(17,18)$ may be a result of the lack of normal vascular wall support, which may have a direct or indirect effect on the process of cardiac outflow septation and alignment. It might initiate a cascade of events responsible for development of cardiovascular structures in the pharyngeal apparatus and upstream to the outflow tract and heart through the endothelial cell column or bloodstream. In preliminary studies using digestions of the tissue homogenates with testicular hyaluronidase and chondroitinase $A B C$ prior to IEF, we found several proteins that were shifted following digestion. Only the one mentioned above disappeared following the digestion in comparing the protein patterns in experimental versus sham-operated embryos. This indicates that the proteins associated with the presence of the neural crest are probably not incorporated in the glycoconjugates of the extracellular matrix.

Since development of the normal glandular derivatives of the pharyngeal apparatus depends on an intact neural crest $(1,3)$, any of these proteins could be involved in development of noncardiovascular structures in the pharyngeal apparatus. This includes thymus, thyroid, and parathyroid glands $(3,4)$.

The remaining proteins expressed in the absence of neural crest cells may be normally suppressed or transformed by cardiac neural crest cells, or they may be produced as a compensatory response to their absence. In regard to the latter possibility, it has been shown that cells derived from the nodose placodes reconstitute neural and some ectomesenchymal cells that participate in cardiovascular development when the cardiac neural crest is removed $(13,15)$. Interestingly, cells from the nodose placodes begin their migration at stage 14 (30), an age at which we identified only one atypical protein in the pharyngeal apparatus of experimental embryos. By stage 18, when three atypical proteins are found in the experimental pharyngeal region, cells derived from the nodose placodes are well established in the pharyngeal region (30). 
A second possibility is that, under normal conditions of development, these atypical proteins are suppressed by the cardiac neural crest cells as they populate the pharyngeal apparatus. There is some evidence that the neural crest cells can alter their migratory pathway as they migrate through an area. Unfortunately, we have not been able to obtain reliable results using IEFSDS-PAGE in the pharyngeal region of embryos younger than stage 14.

There is an additional possibility that some of the proteins expressed in the experimental embryos are heat-shock proteins that are induced in response to the heat of cauterization. However, only one protein is found in experimental embryos at stage 14 ( $24 \mathrm{~h}$ after the cauterization), whereas three are found at stage 18 (48 $\mathrm{h}$ after cauterization). This time course of activation does not fit the usual pattern of heat-shock proteins which are expressed transiently within a few hours of the heat stress (32). It might be possible that some of the proteins at stage 18 are heatshock proteins that are expressed in response to hemodynamic stress caused by neural crest absence. It is well documented that hemodynamic stress can induce the expression of heat-shock proteins (32), and it is also well documented that neural crest ablation results in hemodynamic changes that can be measured at stage $18(17,18)$.

The role of these proteins in the pharyngeal apparatus can only be defined after sequencing and classification of the proteins. It will be essential to generate $\mathrm{MAb}$ or nucleotide probes to determine which cell types these proteins are associated with in the pharyngeal region.

This is a preliminary report in a continuing study to elucidate the role of the cardiac neural crest cells in the pharyngeal apparatus at the molecular level. Identification of proteins in the pharyngeal apparatus expressed either by or in response to cardiac neural crest cells will ultimately lead to a better understanding of the role and mechanism of action of this cell population in cardiovascular development.

Acknowledgments. The authors thank Harriett Stadt and Donna Kumiski for help in production of the experimental embryos and Leslie Hancock for help in setting up the system IEF-SDS-PAGE.

\section{REFERENCES}

1. Kirby ML, Waldo KL 1990 Role of neural crest in congenital heart disease. Circulation 82:332-340

2. Nishibatake M, Kirby ML, Van Mierop LHS 1987 Pathogenesis of persistent truncus arteriosus and dextroposed aorta in the chick embryo after neural crest ablation. Circulation 75:255-264

3. Bockman DE, Kirby ML 1984 Dependence of thymus development on derivatives of neural crest. Science 223:498-500

4. Van Mierop LHS, Kutsche LM 1986 Cardiovascular anamolies in DiGeorge syndrome and importance of neural crest as a possible pathogenic factor. Am J Cardiol 58:133-137

5. Kuratani SC, Kirby ML 1991 Initial migration and distribution of the cardiac neural crest in the avian embryo: an introduction to the concept of the circumpharyngeal crest. Am J Anat 191:215-227

6. Bockman DE, Redmond ME, Kirby ML 1989 Alteration of early vascular development after ablation of cranial neural crest. Anat Rec 225:209-217
7. Le Lièvre CS, Le Douarin NM 1975 Mesenchymal derivatives of the neura crest: analysis of chimeric quail and chick embryos. J Embryol Exp Morpho 34:123-154

8. Le Douarin NM 1981 The Neural Crest. Cambridge University Press, Cambridge, $\mathrm{MA}$

9. Miyagawa ST, Waldo KL, Tomita H, Kirby ML 1989 Migration of cardiac neural crest cells: a temporospatial study in early quail-chick chimeras. NY Acad Sci 588:427-429

10. Kirby ML 1989 Plasticity and predetermination of mesencephalic and trunk neural crest transplanted into the region of the cardiac neural crest. Dev Biol 134:402-412

11. Sundin OH, Eichele G 1990 A homeo domain protein reveals the metameric nature of the developing chick hindbrain. Genes Dev 4:1267-1276

12. Lumsden A, Sprawson N, Graham A 1991 Segmental origin and migration of neural crest cells in the hindbrain region of the chick. Development 113:1281-1291

13. Kirby ML 1988 Nodose placode contributes autonomic neurons to the heart in the absence of cardiac neural crest. J Neurosci 8:1089-1095

14. Kirby ML, Aronstam RS, Buccafusco JJ 1985 Changes in cholinergic parameters associated with conotruncal malformation in embryonic chick hearts. Circ Res 56:392-401

15. Kirby ML 1988b Nodose placode provides ectomesenchyme to developing chicken heart in the absence of cardiac neural crest. Cell Tissue Res 252:1722

16. Rosenquist TH, Beall AC, Modis L, Fishman R 1990 Impaired elastic matrix development in the great arteries after the ablation of the cardiac neural crest. Anat Rec 226:347-359

17. Leatherbury L, Gauldin HE, Waldo K, Kirby ML 1990 Microcinephotography of the developing heart in neural crest ablated chick embryos. Circulation 18:1047-1057

18. Tomita H, Connuck DM, Leatherbury L, Kirby ML 1991 Relation of early hemodynamic changes to survival and cardiac phenotype after neural crest ablation in chick embryos. Circulation 84:1289-1295

19. Narayanan CH 1970 Apparatus and current techniques in preparation of avian embryos for microsurgery and for observing embryonic behavior. Bioscience 10:868-871

20. Hamburger V, Hamilton HL 1951 A series of normal stages of the chick embryo. J Morphol 88:49-92

21. Garrels JI 1979 Two-dimensional gel electrophoresis and computer analysis of protein synthesized by clonal cell lines. J Biol Chem 254:7961-7977

22. Walsh KA 1975 Unifying concepts among proteases. Reich E, Rifkin DB, Shaw E (ed). Proteases and Biological Control. Cold Spring Harbor Lab, Cold Spring Harbor, ME, pp 1-13

23. O'Farrell PH 1975 High resolution two-dimensional electrophoresis of proteins. J Biol Chem 250:4007-4021

24. O'Farrell PZ, Goodman GM, O'Farrell PH 1977 High resolution two-dimensional electrophoresis of basic as well as acidic proteins. Cell 12:1133-1142

25. Bradford DA 1976 Rapid and sensitive method for quantitation of microgram quantities of protein utilizing the principle of protein dye binding. Ann Biochem 72:248-254

26. Laemmli UK 1970 Cleavage of structural proteins during the assembly of the head of bacteriophage T4. Nature 277:680-685

27. Kitten GT, Markwald RR, Bolender DL 1987 Distribution of basement membrane antigens in cryopreserved early embryonic hearts. Anat Rec 217:379-390

28. Baldwin HS, Solursh M 1989 Degradation of hyaluronic acid does not prevent looping of the mammalian heart in situ. Dev Biol 136:555-559

29. Weber K, Pringle JR, Osborn M 1972 Measurement of molecular weights by electrophoresis on SDS-acrylamide gel. Methods Enzymol 26:3-27

30. D'Amico-Martel A 1982 Temporal patterns of neurogenesis in avian cranial sensory and autonomic ganglia. Am J Anat 163:351-372

31. Kuratani SC, Miyagawa-Tomita S, Kirby ML 1991 Development of cranial nerves in the chick embryo with special reference to the alterations of cardiac branches after ablation of the cardiac neural crest. Anat Embryol 183:501514

32. Kochevar DT, Aucoin MM, Cooper J 1991 Mammalian heat shock proteins: an overview with a systems perspective. Toxicol Lett 56:243-267 